\section{Demographic features, clinical characteristics, and prognostic factors of non-epithelial ovarian tumors at Princess Noorah Oncology Center, National Guard Hospital, Jeddah, Saudi Arabia}

\author{
Atheel L. Balkhy, MD, Eiman R. Saleh, MD, \\ Heyam I. Jabali, MD, Hatim M. Al-Jifree, MD, FRCSC, \\ Abmad B Alwazzan, MD, FRCSC.
}

\section{ABSTRACT}

Objectives: To reveal the demographic features, prognostic factors, and tumor characteristics of patients with non-epithelial ovarian tumors (NEOTs).

Methods: This cross-sectional study was performed using data from all female patients diagnosed with NEOT (germ cell [GC], sex cord-stromal cells [SCSC], sarcoma, and small cell carcinoma) from 2002 to 2017 at Princess Noorah Oncology Center, National Guard Hospital Jeddah, Saudi Arabia.

Results: Forty patients with NEOTs were identified. There were equal percentages of GC (45\%) and SCSC (45\%) origin tumors, and these were the most common histological types. The remaining tumors were sarcomas. Germ cell tumors were more common in younger patients, while SCSC tumors were more frequent in the older age group.

Conclusion: The findings for protective and risk factors were inconclusive. Patients with GC tumors had better survival outcomes than those with the other subtypes.

Keywords: non-epithelial ovarian cancer, germ cell tumor, sex cord-stromal cell tumor, demographics, histopathology

Saudi Med J 2022; Vol. 43 (2): 208-212 doi: 10.15537/smj.2022.43.2.20210433

W ith more than 200,000 diagnoses annually worldwide, ovarian cancer is the seventh most common type of cancer among women. ${ }^{1}$ Ovarian tumors can be categorized into epithelial and nonepithelial ovarian tumors (NEOTs), according to cell origin. Most ovarian tumors are epithelial in origin, whereas only $10 \%$ of ovarian cancers are non-epithelial tumors. $^{2-3}$
Ovarian germ cell (GC) tumors are more likely to be found in young women, and the peak tumor incidence occurs at 15 to 19 years of age. ${ }^{2}$ Sex cord-stromal cell (SCSC) tumors are more likely to affect adult women between the ages of 30 to 59 years. ${ }^{2}$ One significant protective factor of GC tumors is the use of oral contraceptives, which reduces the chance of developing ovarian cancer by $20 \%$ if used for 5 years. ${ }^{1}$ In addition, multiparity, breastfeeding, and bilateral tubal ligation are protective factors. ${ }^{1}$ The risk factors for developing neoplasm include increased body mass index (BMI) and hormone replacement therapy. ${ }^{1}$ Various studies found overall good prognosis and survival rates for NEOT. ${ }^{2,4,5}$ However, etiologies and best management practices of NEOT remain poorly understood due to disease rarity and lack of study results. ${ }^{2}$

The most common types of NEOTs are GC tumors tumors with incidence values of 4 per 1,000,000 and SCSC with incidence values of 2 per 1,000,000 women. ${ }^{6}$ Collectively, sarcomas and small cell carcinomas are extremely rare; they are approximately $0.1 \%$ of ovarian malignancies. ${ }^{6}$ In a study carried out in Saudi Arabia, the prevalence of ovarian tumors was $4.1 \%$, which was comparable to US prevalence and that of other developed countries (3\%). ${ }^{7}$ The study also found that malignant ovarian GC tumors comprised $13 \%$ of all ovarian tumors in that same time period (12\%).

The rarity of NEOTs is one important reason for the lack of information on these tumors. This problem is not limited to a specific geographic area; it is relevant on an international level. Small sample sizes contribute to the difficulties in identifying prognostic, protective, and risk factors. Locally, the only study found focused on malignant GC tumor subtypes and included data up to 2008 only. $^{7}$ More research is required to increase the knowledge on NEOTs in the Kingdom of Saudi Arabia.

The objective of this study is to reveal the demographic features, prognostic factors, and tumor characteristics of patients with NEOTs who were admitted to Princess Noorah Oncology Center, National Guard Hospital, Jeddah, Saudi Arabia between January 2002 and July 2017.

Methods. This cross-sectional study was performed using data from all female patients diagnosed with

Disclosure. Authors have no conflict of interests, and the work was not supported or funded by any drug company. 
NEOT from 2002 to 2017 at Princess Noorah Oncology Center, National Guard Hospital, Jeddah, Saudi Arabia. The inclusion criteria was all female patients diagnosed with NEOT from 2002 to 2017. While the exclusion criteria was patients with tumor histological findings indicating mixed or poorly differentiated ovarian cancers. No power analysis to estimate sample size was performed because all of NEOT patients at Princess Noorah Oncology Center, Jeddah, Saudi Arabia were included in the study population. Data were extracted from medical records. Records included demographic information, tumor histopathology and stage, tumor risk and protective factors, treatment modality, and patient status.

Data was collected by the research team using an electronic sheet (Excel). The data was divided into 5 sections: first section included demographic features of the study subjects, such as age, age at diagnosis, nationality, and BMI. The second section specified the cancer histopathological subtype (GC, SCSC, small cell carcinoma, or sarcoma) and stage according to the International Federation of Gynecology and Obstetrics (FIGO) staging classification. ${ }^{8}$ The third section included the patients' medical histories, which also included all ovarian cancer risks and protective factors, namely, smoking, hypertension, infertility and infertility treatment, hormonal replacement therapy, oral contraceptive pills, bilateral tubal ligation surgery, family history of malignancies, and breast-feeding. A clear lack of documentation in the patients' files in regard to any of these factors was considered as "unknown". The fourth section listed the treatment modalities, including surgery and chemotherapy. The fifth section included disease outcomes, namely, in remission, still receiving treatment, died of cancer, died from treatment complication, other, and unknown. In remission was defined as 5 years with no relapse or recurrence. All personal information and data were anonymous and kept in an electronic format under secure conditions.

Statistical analysis. Data were analyzed using SPSS for Windows, version 20 (IBM Corp., Armonk, N.Y., USA). All categorical variables were summarized as frequencies and percentages. Skewed distribution numerical variables were presented as median and interquartile range values. For bivariate analyses, Chi-squared tests were used to analyze categorical data. A $p$-value of $<0.05$ was considered statistically significant.

Results. Among all the female patients diagnosed with ovarian cancer between January 2002 until July 2017 at Princess Noorah Oncology Center $(n=309)$, only $40(13 \%)$ participants met the inclusion criteria, 48 (15\%) participants' data were missing, and the remaining $222(72 \%)$ patients were of epithelial origin and therefore excluded.

Forty patients with NEOTs were identified. The median age at diagnosis of the NEOT patients was 33 years old with an interquartile range of 30 years old. Other demographic features of the participants are shown in Table 1 along with NEOT risk and protective factors prevalence among the study subject. Table 2

Table 1 - Patients' demographic features and non-epithelial ovarian tumor risk and protective factors $(\mathrm{N}=40)$.

\begin{tabular}{|c|c|}
\hline Variables & n (\%) \\
\hline $\begin{array}{l}\text { Age at diagnosis } \\
\text { (median[interquartile range]) years }\end{array}$ & 33 [30] \\
\hline $\begin{array}{l}\text { Young }(<30) \\
\text { Older }(\geq 30)\end{array}$ & $\begin{array}{l}18(45.0) \\
22(55.0)\end{array}$ \\
\hline $\begin{array}{l}\text { Nationality } \\
\text { Saudi } \\
\text { Non-Saudi }\end{array}$ & $\begin{array}{c}38(95.0) \\
2(5.0)\end{array}$ \\
\hline $\begin{array}{l}\text { Body mass index } \\
\text { Underweight } \\
\text { Normal } \\
\text { Overweight } \\
\text { Obese } \\
\text { Extremely obese }\end{array}$ & $\begin{array}{c}5(12.5) \\
9(22.5) \\
7(17.5) \\
7(17.5) \\
12(30.0)\end{array}$ \\
\hline $\begin{array}{c}\text { Smoking } \\
\text { Yes } \\
\text { No }\end{array}$ & $\begin{array}{c}1(2.5) \\
39(97.5)\end{array}$ \\
\hline $\begin{array}{c}\text { Hypertension } \\
\text { Yes } \\
\text { No }\end{array}$ & $\begin{array}{c}7(17.5) \\
33(82.5)\end{array}$ \\
\hline $\begin{array}{c}\text { Infertility } \\
\text { Yes } \\
\text { No }\end{array}$ & $\begin{array}{l}5(12.5) \\
35(87.5)\end{array}$ \\
\hline $\begin{array}{l}\text { Infertility treatment } \\
\text { Yes } \\
\text { No }\end{array}$ & $\begin{array}{c}5(12.5) \\
35(87.5)\end{array}$ \\
\hline $\begin{array}{l}\text { Hormonal replacement treatment } \\
\text { Yes } \\
\text { No } \\
\text { Unknown }\end{array}$ & $\begin{array}{c}1(2.5) \\
20(50) \\
19(47.5)\end{array}$ \\
\hline $\begin{array}{l}\text { Oral contraceptive pills } \\
\text { Yes } \\
\text { No } \\
\text { Unknown }\end{array}$ & $\begin{array}{c}0 \\
19(47.5) \\
21(52.5)\end{array}$ \\
\hline $\begin{array}{l}\text { Bilateral tubal ligation surgery } \\
\text { Yes } \\
\text { No } \\
\text { Unknown }\end{array}$ & $\begin{array}{c}0 \\
26(65.0) \\
14(35.0)\end{array}$ \\
\hline $\begin{array}{l}\text { Family history of malignancies } \\
\text { Yes } \\
\text { No } \\
\text { Unknown }\end{array}$ & $\begin{array}{c}4(10.0) \\
35(87.5) \\
1(2.5)\end{array}$ \\
\hline $\begin{array}{l}\text { Breast feeding } \\
\text { Yes } \\
\text { No } \\
\text { Unknown }\end{array}$ & $\begin{array}{c}0 \\
19(47.5) \\
21(52.5)\end{array}$ \\
\hline
\end{tabular}


Table 2 - Tumor stages and histopathology subtypes, treatment modality, recurrence rate and patient status $(\mathrm{N}=40)$.

\begin{tabular}{|c|c|}
\hline Variables & n (\%) \\
\hline \multicolumn{2}{|l|}{ Histopathology subtype } \\
\hline Germ cell tumor & $18(45.0)$ \\
\hline Sex cord-stromal & $18(45.0)$ \\
\hline Sarcoma & $4(10.0)$ \\
\hline \multicolumn{2}{|l|}{ Histopathology subtype } \\
\hline Germ cell tumor & $18(45.0)$ \\
\hline Sex cord-stromal & $18(45.0)$ \\
\hline Sarcoma & $4(10.0)$ \\
\hline \multicolumn{2}{|l|}{ Tumor stage (early/late) } \\
\hline Early (FIGO stage $2 \mathrm{~B}$ and below) & $22(55.0)$ \\
\hline Late (FIGO stage $3 \mathrm{~A}$ and later) & $14(35.0)$ \\
\hline Unknown & $4(10.0)$ \\
\hline \multicolumn{2}{|l|}{ Surgical procedure } \\
\hline \multicolumn{2}{|l|}{ Biopsy } \\
\hline Yes & $40(100.0)$ \\
\hline No & 0 \\
\hline \multicolumn{2}{|l|}{ Suboptimal cytoreductive surgery } \\
\hline Yes & $12(30.0)$ \\
\hline No & $17(42.5 .0)$ \\
\hline Unknown & $11(27.5 .0)$ \\
\hline \multicolumn{2}{|l|}{ Optimal cytoreductive surgery } \\
\hline Yes & $17(42.5)$ \\
\hline No & $12(30)$ \\
\hline Unknown & $11(27.5)$ \\
\hline \multicolumn{2}{|l|}{ Other surgeries } \\
\hline Yes & $9(17.5)$ \\
\hline No & $31(82.5)$ \\
\hline \multicolumn{2}{|l|}{ Chemotherapy\# of chemotherapy } \\
\hline No chemotherapy & $11(27.5)$ \\
\hline 1 line chemotherapy & $20(50.0)$ \\
\hline$>1$ line chemotherapy & $9(22.5)$ \\
\hline \multicolumn{2}{|l|}{ Recurrence } \\
\hline Yes & $20(50.0)$ \\
\hline No & $7(17.5)$ \\
\hline \multirow{2}{*}{\multicolumn{2}{|c|}{ Patient status }} \\
\hline & $21(52.5)$ \\
\hline On remission & $5(12.5)$ \\
\hline Still on treatment & $6(15.0)$ \\
\hline $\begin{array}{l}\text { Died of cancer } \\
\text { Unknown }\end{array}$ & $8(20.0)$ \\
\hline
\end{tabular}

provides tumor stage and histopathology subtypes, treatment modality, recurrence rate and patient status.

There was a significant correlation between age and histopathology subtype with a $p<0.001$. Patients $<30$ years old were mostly diagnosed with GC (17 [94.4\%]), and only one $(5.6 \%)$ patient was found to have sarcoma. However, patients $>30$ years old were diagnosed with SCSC (18 [81.8\%]), 3 (13.6\%) had sarcoma, and one (4.5\%) had GC.

Figure 1 illustrates the survival outcome of each histopathological subtypes of non-epithelial ovarian cancer, which showed significant difference according to the Chi square test $(p=0.043)$.

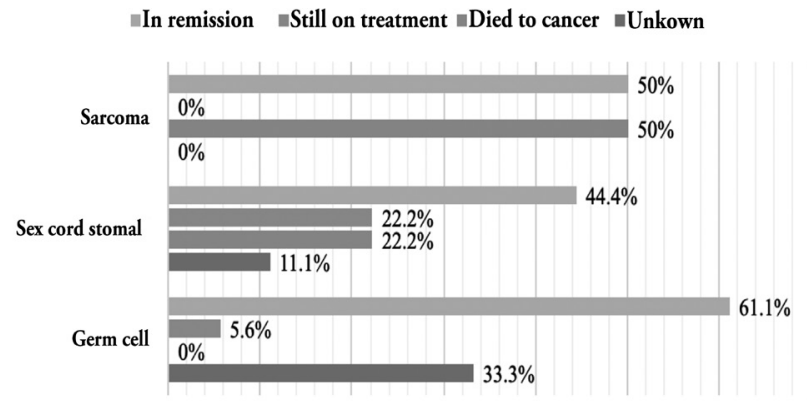

Figure 1 - Bar graphs of survival outcomes for each histopathological subtype of non-epithelial ovarian cancer $(p=0.043)$.

Discussion. This study found that the incidence of NEOTs was $13 \%$ for all ovarian tumors. Germ cell and SCSC tumors each accounted for $5.8 \%$ of all ovarian tumors, while sarcomas accounted for $1.3 \%$. This finding can be considered somewhat high compared with other international studies with larger sample sizes. A study carried out in the USA found incidence rate of $3 \%$ for GC tumor and 2\% for SCSC tumor. ${ }^{9}$ The current study found that GC and SCSC tumors had the highest incidence values among all the histopathological subtypes of NEOTs ( $45 \%$ each). International findings in the Netherlands found that $60 \%$ of GC tumors are NEOTs, and $27 \%$ are SCSC tumors. ${ }^{10}$ This variation in incidence might be due to the smaller sample size in our study $(\mathrm{n}=40)$ compared with that of Netherlands study $(n=1258)$. However, the Netherlands study estimated the incidence of sarcoma as $13 \%$, which was comparable to our finding of $10 \% .{ }^{10}$

When examining whether specific histopathological subtypes were related to the age of the patient at diagnosis, we divided the study subjects into a younger age group $(<30$ years) and an older age group $(\geq 30$ years). We found that GC tumors had a younger age distribution. This result was consistent with the findings of Torre et al. ${ }^{9}$ Sex cord-stromal cell tumors were mostly found in the older age group.

The results of this study were inconclusive regarding the prognostic and risk factors mostly due to the small sample size and missing patient data. However, despite the known protective effect of breastfeeding on ovarian tumors, almost one-half of our patients were non-breast feeders $(47.5 \%)$. The high percentage of non-breast feeders might be explained by the inability to breastfeed (because of young age (pediatric), being unmarried, or both).

Surgery is the cornerstone of treatment for most stages of NEOTs. ${ }^{10}$ For this study, we examined whether the surgery outcome (optimal or suboptimal) 
was affected by histopathological subtype to identify whether some tumors are more aggressive and therefore result in suboptimal surgery outcomes. This study found that $44.4 \%$ of patients with GC tumors had an optimal surgery and $27.8 \%$ had a suboptimal surgery. The remaining $27.8 \%$ had an unknown type of surgery. Sex cord-stromal cell tumors were associated with a similar percentage of optimal surgeries (44.4\%) and a slightly higher percentage $(33.3 \%)$ of suboptimal surgeries compared to GC tumors. The remaining $22.2 \%$ had an unknown type of surgery. For sarcomas, of the 4 cases found, $1(25 \%)$ had an optimal surgery, $1(25 \%)$ had a suboptimal surgery, and $2(50 \%)$ had an unknown surgery outcome. Because the percentages of optimal and suboptimal surgeries were somewhat comparable, no significant relationship was found between the type of surgery performed and tumor histopathology. Surgery type also did not significantly affect the recurrence rate.

Tumors that are more aggressive require more than one line of chemotherapy to achieve remission. In this study, we examined whether the need for more than one line of chemotherapy was related to worse outcomes. Patients were divided into 3 groups (no chemotherapy use, one line of chemotherapy, and more than one line of chemotherapy). More than three-quarters of those that received more than one line of chemotherapy had tumors in remission $(77.8 \%), 63.6 \%$ of patients that did not receive chemotherapy had tumors in remission, and $35 \%$ of those that were given with one line of chemotherapy had tumors in remission. One-fifth of patients $(20 \%)$ from the one line of chemotherapy group died of cancer compared with those that received more than one line of chemotherapy (11.1\%). Although this difference was statistically insignificant, the reason behind this result was not understood.

Patient outcomes were found to be significantly affected ( $p=0.043)$ by tumor histopathology. The results indicated that $61.1 \%$ of the patients who had a GC tumor diagnosis were in remission at the end of the study period, no death cases were reported in the records and the outcome of $33.3 \%$ of the patients were unknown due to loss to follow-up. This result can be explained by the excellent prognosis for GC tumors. ${ }^{6}$ For SCSC tumors, $44.4 \%$ of patients had tumors in remission, and $22.2 \%$ died from cancer. Torre et $\mathrm{al}^{9}$ found that both GC and SCSC tumors have high 5-year survival rates of 99\% for GC and 98\% for SCSC. Survival rates remain relatively high even for FIGO stage IV disease. ${ }^{9}$

However, patient outcomes were not affected by FIGO tumor staging at the time of diagnosis. Of the patients with early-stage disease (FIGO stage 2B and below), 59.1\% had tumors in remission at the end of the study period. A slightly lower proportion (42.9\%) of the late-stage group (FIGO stage $3 \mathrm{~A}$ and later) had tumors in remission. The difference in outcomes between the 2 groups was statistically insignificant $(p=0.547)$. This result contrasted with those of other studies that found that FIGO staging at the time of diagnosis is strongly associated with survival for both GC and SCSC tumors. ${ }^{10}$

Study limitations. The smaller sample size and missing data were limitations of this study. We recommend that a similar study be conducted through the Saudi Cancer Registry or on a multicenter level throughout the Saudi Arabia to better understand the effects of NEOTs in the Saudi population.

In conclusion, most NEOTs are presented with GC and SCSC histopathology. Germ cells tumors are more common in younger patients, and SCSCs are more common in older patients. Patients with GCs showed better survival outcomes than those with the other subtypes in this study.

Acknowledgment. We gratefully acknowledge Falcon Scientific Editing for the English language editing.

Received 21st September 2021. Accepted 7th December 2021.

From the College of Medicine (Balkhy, Saleh, Jabali), King Saud Bin Abdulaziz University for Health Sciences; from the Department of Oncology (Al-Jifree), King Saud Bin Abdulaziz University for Health Sciences, National Guard Hospital; and from the Department of Oncology (Alwazzan), King Abdulaziz University, Jeddah, Kingdom of Saudi Arabia.

Address correspondence and reprints request to: Dr. Atheel L. Balkhy, College of Medicine, King Saud Bin Abdulaziz University for Health Sciences, Jeddah, Kingdom of Saudi Arabia.E-mail: at.balkhy@gmail.com

ORCID ID: https://orcid.org/0000-0003-4244-0189

\section{References}

1. Reid BM, Permuth JB, Sellers TA. Epidemiology of ovarian cancer: a review. Cancer Biol Med 2017; 14: 9-32.

2. Kempf E, Desamericq G, Vieites B, Diaz-Padilla I, Calvo E, Estevez P, et al. Clinical and pathologic features of patients with non-epithelial ovarian cancer: retrospective analysis of a single institution 15-year experience. Clin Transl Oncol 2017; 19: 173-179.

3. Berek JS, Bast RC Jr. Nonepithelial Ovarian Cancer. In: Kufe DW, Pollock RE, Weichselbaum RR, et al., editors. HollandFrei Cancer Medicine. 6th edition. Hamilton $(\mathrm{ON})$ : BC Decker; 2003.

4. Parkinson CA, Hatcher HM, Ajithkumar TV. Management of Malignant Ovarian Germ Cell Tumors. Obstet Gynecol Surv 2011; 66: 507-514.

5. Matz M, Coleman MP, Carreira H, Salmerón D, Chirlaque MD, Allemani C. Worldwide comparison of ovarian cancer survival: Histological group and stage at diagnosis (CONCORD-2). Gynecol Oncol 2017; 144: 396-404.

6. Boussios S, Zarkavelis G, Seraj E, Zerdes I, Tatsi K, Pentheroudakis G. Non-epithelial ovarian cancer: elucidating uncommon gynaecological malignancies. Anticancer Res 2016; 36: 5031-5042. 
7. Abu-Zaid A, Nazer A, AlOmar O, Azzam A, Al-Eid HS, Elhassan TA, et al. Incidence of malignant ovarian germ cell tumors (MOGCTs) in Saudi Arabia. Hematol Oncol Stem Cell Ther 2014; 7: 41-43.

8. Šišovská I, Minár L, Felsinger $M$, Anton $M$, Bednaříková $M$, Hausnerová J, et al. Current FIGO staging classification for cancer of ovary, fallopian tube and peritoneum. Ceska Gynekol 2017; 82: 230-236.
9. Torre LA, Trabert B, DeSantis CE, Miller KD, Samimi G, Runowicz CD, et al. Ovarian cancer statistics, 2018 [Internet]. CA: a cancer journal for clinicians. CA Cancer J Clin 2018; 68: 284-296.

10. Van der Hel OL, Timmermans M, van Altena AM, Kruitwagen RFPM, Slangen BFM, Sonke GS, et al. Overview of nonepithelial ovarian tumours: Incidence and survival in the Netherlands, 1989-2015. Eur J Cancer 2019; 118: 97-104. 